\title{
THE IDENTIFICATION OF SUSTAINABLE SUPPLY CHAIN ELEMENTS IN THE ENTERPRISE $X$
}

\author{
Paula, Bajdor \\ Czestochowa University of Technology, Czestochowa, Poland, paula.bajdor@gmail.com
}

\begin{abstract}
Today, operating on the market, enterprises, to a lesser or greater extent, try to carry out their activities in such a way to minimize the possible negative impact on the environment. In most companies, the analysis of its supply chains can identify them as "green supply chains", which primarily involves not harming the natural environment. However, the further development of this concept is "sustainable supply chain", the chain that means not only protection of the environment but also means caring for the closest social environment together with economic development of the company. As opposed to green supply chains, it is still difficult to identify a sustainable supply chain in Polish enterprises. For the research purpose, the interview sheet has been created, based on the answers provided by the companies it is possible to further identify and determine the elements that make up a sustainable supply chain. This article presents an interview sheet with the answers given by one of the companies investigated.
\end{abstract}

KEYWORDS: supply chain, green supply chain, sustainable supply chain, enterprise, questionnaire

\section{INTRODUCTION}

In recent years, many authors have defined the term "supply chain" in different ways. Definition, which is closest to understanding the supply chain is the definition given by the European Committee for Standardization, "the supply chain is a sequence of processes to add value to the product during its movement and processing of raw materials, through all the intermediate forms, to form consistent with the requirements of the end customer, "[1]. Other authors, for example, A.J. Stenger and J.J. Coyle define the supply chain as "the integrated management of logistics flow sequences, processing and related support activities - from suppliers to final customers - needed to produce the product or service in an efficient and effective way. [2]

The essence of the classic supply chain is supply of raw materials and processing them into finished products (in one or more businesses), transporting them to the warehouse for storage and transporting the products or goods to the final recipients. The traditional supply chain focuses on production processes, transport and supply, apart from issues related to environmental protection. In traditional supply chain issues of environmental protection able to reduce its degradation, are omitted. For example, the acquisition of raw materials, the classic supply chain does not take into account whether raw materials are extracted from renewable sources or with respect to the environment. Moreover, the issue related to transportation of raw materials, classic supply chain does not take into account whether the mode of transport is the least harmful to the environment. Here the example might be the use of road transport, which emits large amounts of carbon dioxide into the atmosphere instead of using rail transport, which is less harmful.

Green supply chain is defined as "the process of using environmentally-friendly input elements, and then transform those elements into products that can be recycled or discharged to the environment. The end result of this process is to obtain goods or finished products that can be recycled or reused at the end of their life cycle "[3]. The idea of green supply chain is to reduce the costs of assisted simultaneous immediate environment [4]. In the past, most companies have focused on minimizing costs, but later, many of them have changed their behavior, looking at all costs incurred by them. They have also started to recognize the cost per unit, such as printing one side of the paper.

Next to the above definitions, we can also highlight the reverse supply chain, which is defined as actions taken to recover the product from the client and then directed to the process of reuse or disposal. [5]

In the future, more and more enterprises will undertake the direction of green supply chains, as the current reality makes it necessary to change the currently used supply chain in order to maintain the existing sources of raw materials for future generations. Green supply chain not only causes that companies can significantly reduce costs and help the environment, but green supply chain is also just a "good thing".

\section{THE IDENTIFICATION OF SUSTAINABLE SUPPLY CHAIN ELEMENTS}

Sustainable supply chain not only includes areas related to the environment but also the society and economic development. Sustainable chain may be some extension of green supply chain. According to Patrick Penfield, companies seeking to create a sustainable supply chain should carry out the following activities [6]:

- the first step should be the change of paradigm by which most of the companies operate, it says that "all actions are allowed in accordance with the law, no matter how they may affect the environment." In order to change this approach, business leaders should be trained in order to be aware of its business impact on the environment and take action to minimize these negative actions,

- implementation of the concept of sustainable development into the whole company, show all the employees the 
benefits of the concept of sustainable development, not only for the environment but also for the entire company,

- the audit of the supply chain in the company, in terms of sustainable development, enables to determine at what stage of sustainable development company is, and find out what still has to be done. Conducted audit should focus on the following areas: energy consumption, environmental costs, the recovery of raw materials, water, transport, hazardous materials and products, processes, reverse logistics, packaging and social responsibility,

- the results of the audit may indicate the company, which the next step is to define the goals and objectives of sustainable supply chain. In the process of identifying these goals and objectives, a company must be aware that they are "SMART" - Specific, Measurable, Attainable, Relevant and Timely (well-defined, measurable, realistic, relevant and up to date) and that they are consistent with the concept sustainable development,

- the next step is to determine the action need to be taken in order to achieve the goals and tasks. To make this possible, the company should prepare a plan and develop projects whose end result would let to achieve the objective of sustainable development in the company. It is a long process and it may take many years,

- after the project's development, the next step is to measure the progress of the implementation of sustainable development. These measurements are carried out to determine the effectiveness of the implemented project,

- the last step is checking not only the current level of sustainability in the supply chain, but also looking at other companies and their activities in this direction. Using their solutions can help to increase the level of sustainability in the supply chain and accelerate the processes and actions in the company.

Sustainable supply chain management is a strategy, transparency, integration and achieving social, environmental and economic objectives of the company. These objectives are achieved in accordance with the key business activities that affect long-term economic development of enterprises and their supply chains [7].

All areas of the environment, society and economic development are linked to each other. Tasks included in the area of environmental protection, are well realized when they are carried out together with the activities related to the organizational culture of the company. These actions are based on the improvement of supply chain processes so its negative impact on the environment is less harmful. In order to minimize the (negative) impact of those activities, they should be closely related to the economic development of the company. The same applies to the activities of the organizational culture, which has a direct impact on the immediate environment of social organization. Activities in this area are based on improving the flow in the supply chain between the employees and shareholders of the company.

Better effect of these actions will be achieved in connection with a company's activity characterized by economic development. On the other hand, measures which affect the economic development of the company, are the supply chain processes, which are easiest to measure in terms of their effectiveness and efficiency, and they are the most important part of the company's activity.

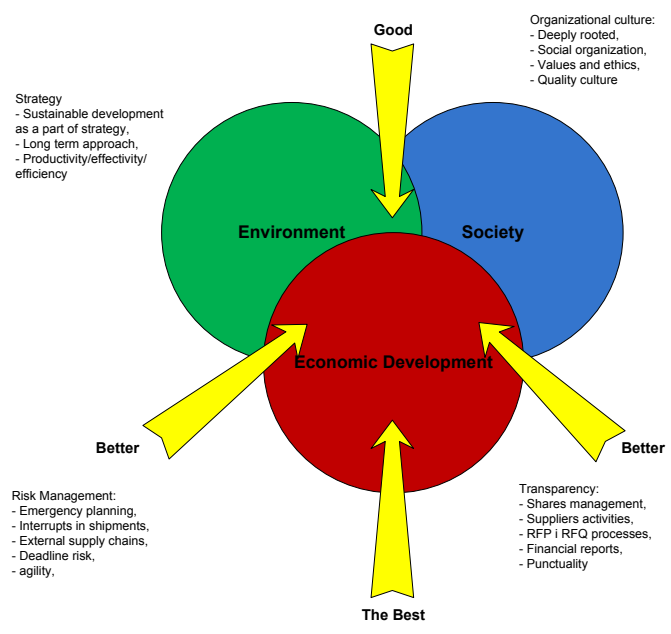

Figure 1. Sustainable supply chain. [7]

However, the most effective supply chain management will be achieved if the company combines these three areas, and its activities will focus simultaneously on all these areas. The activities in the field of protection and care for the environment as well as enhance organizational culture, can be afforded by the companies characterized by stable economic growth. Effective and efficient, in terms of economy, processes within a supply chain, significantly contribute to an increase in activities aimed at the environmental and social areas.

\section{SUSTAINABLE SUPPLY CHAIN IN THE ENTERPRISE}

In this section, the interview conducted in a company $\mathrm{X}$ in order to identify the essential features of a sustainable supply chain, will be presented.

Company $\mathrm{X}$ is a company that manufactures pushchairs and children's products. It has been operating on the market for more than 50 years, and now has gained a strong position thanks to the high quality of the products as well as design and innovation. In the production of its goods, the company cooperates with professionals in the field of design and in the production process the latest technology and design solutions are being used.

The nature of the business creates a supply chain, typical of the processes within the company:

- The process of acquiring supplies or raw materials or semi-finished products from external suppliers,

- The process of transporting raw materials to the storage company,

- The process of storage - warehouse is used for storage of raw materials from suppliers and the finished products as well,

- The distribution process - which consists of a transport process which aim is to provide a finished products to retailers, and then to the end users.

However, the most important processes in the company are the processes of transport and storage that is why they were the subjects of a conducted interview. The detailed discussions made it possible to identify the elements that make the company X supply chain a sustainable one.

Below are the questions and answers in the interview, which clearly imply the practical use of the concept of sustainable development elements in the company X supply chain.

1. Does the company control its suppliers? 
The company has suppliers from China, Italy and Ukraine. From China the final products and components such as wheels, fasteners and upholstery for seats are transported. From Italy bodies of car seats, and from Ukraine - car seats frames. The local suppliers provide other baby accessories.

Each batch is tested at random trolleys, about $5 \%$ of the total transport is subjected to quality control. When a discrepancy is found, the whole lot is controlled.

Deliveries from Italy and Ukraine are transported by a courier company paid by the supplier. The frequency of the deliveries is about 10-12 thousand pieces of goods every two months. Deliveries from China are transported by ship to the port of Antwerp, and then the containers are moved onto trucks from courier companies and goods are transported to a place of business. China deliveries frequency is dependent on the period in the season, the period covering the months of FebruaryMarch-April - deliveries are made once a month. Throughout May-August, which is a peak season, deliveries are made once a week. In the period from September to November - once a month, and from December to February - there are no deliveries during off-peak season.

Control of China suppliers takes place in such a way that every 3 months, supply manager, is going to China factory in order to visually check the conditions of work in the prevailing. The company primarily tries to cooperate with factory, which doesn't hire prisoners. Supply manager also checks the cleanliness and condition of the machinery and equipment, as well as social conditions offered to employees.

Control of Italian suppliers is rather a courtesy visit, as Italy as a European country and a EU member for several years as well, Italian factory meets all hiring standards.

In the case of co-operation with the Ukrainian supplier, before the start of the cooperation, the representative of the company has been sent to factory, whose task was to provide know-how on quality standards, which the Ukrainian supplier must introduce. Also, he provided all the necessary information regarding salary and social conditions for workers employed by the supplier to Ukraine.

However, the control on the local suppliers is still not being carried out.

\section{Are deliveries planned correctly?}

Orders for trucks are made in the January, and they must be paid by the end of February. However, delivery of ordered products takes place in between May-September. As can be seen from the above, there is a large interval between the time of order and the actual delivery. Such a large time period is caused by the fact that in the case of deliveries from China by sea, a company must be aware of unforeseen accidents and thus should have the appropriate time frame to respond to unforeseen delays.

However, deliveries to final recipients are carried out every day. To provide the products, the company uses the services of a DPD courier company.

3. Do the pallets are configured in a such way that the load space is used in the most effectively way?

In the case of suppliers - delivered products are stuffed in containers so that employees often have a problem with its unpacking. However, in the case of shipment of goods to endusers - this is duty of a courier company.
4. Do you use the pallets, packages or cardboard, which can be recycled for Re-use?

Ready pushchairs are imported in boxes that are the end-used packaging, which then goes to the store. Parts of the car seats are packed in boxes of 500 pieces, as well as the bodies of the car seats. Frames for car seats usually are packed in cardboard boxes and Styrofoam pellets immersed in.

All packaging used are directed to recycled process.

5. Have you considered using a railway transport instead of car mode?

No, there was no need.

6. Does the company consider the cooperation with other company to consolidate the deliveries?

For deliveries to the company - all the containers are filled in such a way that it is not possible to add any other goods. For deliveries to customers, it depends on the courier company but where there is a possibility to add any additional containers, the courier company does that.

7. Was the storage space organized in a manner to allow its effective use?

Company's warehouse is a modern building built in 2007 . Warehouse has a high storage racks and semi-automatic trolley system is used, whose task is to remove the product from shelves. The degree of use the storage space is close to $90 \%$ almost all the time.

8. Do storage pallets or products use the maximum permissible load storage shelves?

Storage shelves permissible load is permitted only during the peak season when the number of goods stored in the warehouse is almost the maximum, and warehouse space is used in $100 \%$.

9. Has the analysis of differences between the manual and automatic system been conducted?

Yes, such an analysis was carried out immediately after opening the warehouse in 2007. The analysis showed that a fully automatic system would be uneconomical for the warehouse, because of its size (about 2000m2). Therefore, the stock semi-automatic system is used - a list under which the order is completed, and this list, in electronic form, is transferred to the forklift, and the screen displays the location of each item in the warehouse. A person in charge of the forklift pulls up to the point and removes item from the rack.

10. Do the equipment used in the warehouse is quite enough?

In the warehouse, one forklift made by Hitachi is used; this is a very modern forklift, which fulfils all the requirements in regards to noise.

11. When the shifts are set up - are taken into account the requests from the employees?

There is one shift in the warehouse, from $7 \mathrm{am}$ to $3 \mathrm{pm}$, after $3 \mathrm{pm}$, one employee, whose task is to send additional shipments, remains on call. The person performing duty on a given day may come to work two hours later. But in case someone has a special request, like coming to work later or leave earlier, usually are considered positive.

12. Are the shipments configured in a way to minimize the distance between the locations? 
It is a matter of external courier company. The only thing it's been known, is all given to the courier shipments, are sent first to the main office in Lodz, there are then sent to their destination.

13. Are the machines and equipment used to complete the order projected to minimize any risk?

The lift truck used in the warehouse was designed in the way to fulfil the highest safety standards.

14. Are the foils and materials used for final packaging used in the most effective way?

The packages are designed so that it completely fills the truck at the time of unpacking the truck, it becomes impossible to repackage it. In addition, all cartons are designed in such a way that the multiple of its dimensions exactly matches the dimensions of the container in which it is transported.

15. Are the used packages subjected to the recycling process?

Yes, all packaging is recycled. Company has set up three containers for various types of packaging. The first container is designed for cardboard and paper packaging, the second container - stretch film, the third container contains the Styrofoam and fill in which they are immersed bogie frames. The company also has a fourth container in which are stored coconut shells. Coconuts shells are used by the Chinese as a filler when the container has empty space.

16. Was the possibility of changing vehicles taken into account in order to increase the volume of transported goods?

Yes, initially courier company vans were used, but now, because of the size and frequency of shipments, trucks with a capacity of 20tons are used. For deliveries to the company, the trucks transport the goods mostly, because they transport containers.

17. Are the transportation means, delivering goods to the company used to make a delivery to the final recipients?

No, the courier company chosen by the suppliers from China, Italy and Ukraine transports goods delivered to the company. But, in the case of deliveries to the customers, company uses the service of DPD Courier Company.

18. Was the use of alternative fuels considered instead of traditional?

The only vehicle is company's forklift used in a warehouse. It is powered with gas, the most environmentally friendly and most economical fuel.

19. Is a special computer program used for route planning?

Yes, DPD Courier Company uses its own computer program for route planning.

20. How often are the company's vehicles serviced?

The forklift used in the warehouse is being serviced once a year.

21. Has the warehouse been built with the efficient use of energy technology?

Warehouse was built of prefabricates, which allowed to built it within two weeks. On the roof of the warehouse solar panels, which are used to heat water in the warehouse.

22. Has the energetic audit been conducted in the warehouse?
Yes, before the warehouse has been opened, the energy audit had been conducted, which showed that warehouse fulfils the requirements.

23. Is there any possibility that the warehouse could offer its space to other companies?

No, in the warehouse are stored the products of company only.

24. Is the location of the warehouse appropriate?

The warehouse is located next to the production building, where pushchairs are made. Inside the building an internal transport was installed - this is the line on which the finished goods are sent to the warehouse and put on the shelves. One wall of the warehouse and production hall is common.

25. How is the temperature inside the warehouse controlled?

Due to the nature of the goods stored, there is no need to control the temperature. Its level is only controlled in the rooms for employees.

26. Is the warehouse equipped with proper insulation in the door?

Only the doors leading to the employee's rooms are insulated to prevent the heat loss.

27. Is the noise level in the warehouse controlled?

Yes, the noise level in controlled by the inspector on regular basis.

28. What kind of fuels are most often used?

Gas fuel used by the forklift

29. Is the office equipment used in the warehouse working in energy safe mode?

Yes, all office equipment together with the lighting, fulfils the requirement of energy safe mode.

30. Has the system of efficient use of water been installed in the warehouse?

Yes, the water used for washing is taken from the local water supply. Water for drinking is purchased in plastic bubbles. Process water is a closed system, creating two circuits:

- A first cooling water circuit - it has the highest quality, it is $100 \%$ distilled, it occurs in the cooling system and is discharged outside the closed circuit.

- A second water circuit is used to seasoning products - all plastic components end up in the water reservoir, which are cooled and all chemical compounds are washed out, Waste water is then subjected to a process of lagooning water is released to the concrete tank, next to the company, and left there until it disappears.

31. How is the paper consumed?

All office paper is thrown into shredders and then goes to the container in which they are stored in paper cartons and all packaging. A recycling company picks up the container.

32. Does company use a recycled paper?

Company uses only recycled paper - envelopes and postcards.

33. Is there a transportation system used by the company's employees?

There is no transportation system created by a company, but employees form a group in the commute to work. This is an internal matter of the employees. 


\section{ACKNOWLEDGMENT}

Based on the interview, it is possible to identify and define the sustainability in the company's supply chain. Reviewing the publicly available information provided by companies, such as web pages, you can be certain that the sustainable supply chain occurs in each company. However, only a very detailed questionnaire containing questions as well as the received answers can provide accurate clarification of the characteristics that make up a sustainable supply chain. Currently, the questionnaire is sent to the companies, but on the basis of the first interview, it became clear that it requires a few additional questions related to the final distribution process as well as questions related to the activities of the business to the next social environment. The author hopes that the resulting response from the other companies will enable it to develop a report on sustainable supply chains in Polish enterprises.

The concept of sustainable development as well as supply chains, are areas that are subject to constant evolution, an example can be pre-set definitions of green and sustainable supply chain. This evolution is to continuously improve, accelerate and support each activity undertaken by the business units. Skilful implementation and use of previously presented concepts and definitions, is certainly a positive impact on the whole company - to strengthen the position in the markets, increase competitiveness, better image and more to maximize revenue and profit with the continuous increasing efficiency.

\section{REFERENCES}

1. European Committee for Standardization, CEN/TC, Logistics - Structure, Basic Terms and Definitions in Logistics, Brussels 1997.

2. Coyle J.J., Bardi E.J., Langley C.J., „Zarzadzanie logistyczne”, PWE, Warszawa 2002, p. 30.

3. Penfield P., „The Green Supply Chain. Sustainability Can be a Competitive Advantage", Whitman School of Management, Syracuse University 2007.

4. Bajdor P., Grabara I., "Green Supply Chain Operating at the Fashion Market”, Logistyka 6/2012, pp.13-18

5. Starostka-Patyk M., „Reverse Logistics and Environmental Management Aspects in Waste Treatment", w: The Challenges for Reconversion. Innovation - Sustainability Knowledge Management, Ed. by Piotr Pachura, Virton 2006, p. 167

6. Penfield P., "Seven Steps to Implementing a Sustainable Supply Chain”, Whitman School f Management, Syracuse University 2009.

7. Carter C. R., Rogers D.S., „A framework of sustainable supply chain management: moving toward new theory", w: International Journal of Physical Distribution and Logistics Management, vol. 38/5, 2008, p. 366. 